\title{
Construct Validity of Likert Scales through Confirmatory Factor Analysis: A Simulation Study Comparing Different Methods of Estimation Based on Pearson and Polychoric Correlations
}

\author{
María de los Ángeles Morata-Ramírez ${ }^{1}$ \& Francisco Pablo Holgado-Tello ${ }^{1}$ \\ ${ }^{1}$ Methodology of Behavioral Sciences Department, Universidad Nacional de Educación a Distancia (UNED), \\ Madrid, Spain \\ Correspondence: Francisco Pablo Holgado-Tello, Methodology of Behavioral Sciences Department, Universidad \\ Nacional de Educación a Distancia (UNED), C/ Juan del Rosal 10 (Ciudad Universitaria), 28040, Madrid, Spain. \\ Tel: 34-91-398-8648. E-mail: pfholgado@psi.uned.es
}

Received: December 16, 2012 Accepted: December 31, 2012 Available online: January 16, 2013

doi:10.11114/ijsss.v1i1.27

URL: http://dx.doi.org/10.11114/ijsss.v1i1.27

\begin{abstract}
The widespread use of Pearson correlations and, by extension, the Maximum Likelihood estimation method, does not take into account the measurement properties of Likert scales observed variables when carrying out a construct validity process through Confirmatory Factor Analysis (CFA). This simulation study compares four estimation methods (Maximum Likelihood -ML-, Robust Maximum Likelihood -RML-, Robust Unweighted Least Squares -, RULS) according to two of the assumptions CFA is supposed to fulfil: multivariate normality and, especially, the continuous measurement nature of both latent and observed variables. Goodness of fit is diagnosed by $\chi^{2}$ Likelihood Ratio Test and RMSEA indices. Results suggest ULS and RULS are preferable as polychoric correlations help to overcome grouping and transformation errors produced when using Pearson correlations for ordinal observed variables. Data measurement scale consideration enhances the ability of hypothesized models to reproduce accurately construct variables relationships.
\end{abstract}

Keywords: construct validity, Confirmatory Factor Analysis, Likert scales, Pearson correlations, polychoric correlations, estimation methods

\section{Introduction}

In the context of construct validity, factor analysis allows obtaining empirical evidences about the internal structure of a measurement instrument, namely, the relationships between the latent variables and the results obtained after administering the instrument (Ferrando \& Anguiano-Carrasco, 2010). Confirmatory factor analysis (CFA) is a particular case of structural equation modeling (SEM) which consists of collecting data in order to confirm that a construct is defined according to the theoretical approach the researcher uses as a starting point. Then, the model will serve to represent, in a reasonably good way, how the observed variables are interconnected (Schumacker \& Lomax, 1996).

Among the theoretical assumptions CFA sets (Cea, 2004), in this study we will focus on two of them -multivariate normality and, especially, the continuous measurement nature of both latent and observed variables- when using Likert-type scales. In this sense, Likert scales latent variables are considered as continuous, while its observed (measured) variables show ordinal properties and thus one of CFA assumptions is a priori unfulfilled (Cea, 2004).

Maximum Likelihood (ML) is the most popular SEM parameters estimation method given that it provides asymptotically unbiased, consistent parameter estimates (Bollen, 1989; Finch, West, \& MacKinnon, 1997; Muthén \& Kaplan, 1985, 1992; West, Finch, \& Curran, 1995). However, it uses Pearson correlations, which implies the assumption of the continuous measurement nature of both latent and observed variables, apart from multivariate normality (Bollen, 1989; Coenders \& Saris, 1995; DiStefano, 2002). The use of Pearson correlations when analysing Likert scales can lead to grouping and transformation errors (Coenders \& Saris, 1995; DiStefano, 2002; Johnson \& Creech, 1983; O’Brien, 1985), which can be controlled by using polychoric correlations whenever latent variables have a bivariate normal distribution (Coenders \& Saris, 1995; Holgado, Chacón, 
Barbero, \& Vila, 2010). Skewness seems to be the most influential factor when this latter distributional requirement is not fulfilled, especially in case of differences in the direction or the degree of the skewness from variable to variable (Coenders \& Saris, 1995). Even so, Quiroga (1992) found that polychoric correlations are less biased than Pearson correlations do.

Many authors as Bisquerra (1989) state that before assessing the model fit there is a previous CFA step in which estimations of the parameter values take place through an estimation method. From contributions of Batista and Coenders (2000), Cea (2004), Finney and DiStefano (2006), and Mels (2006), four of these estimation methods are compared in this simulation study (Figure 1). Two of them consider that observed variables are of continuous measurement nature - Maximum Likelihood (ML) and Robust Maximum Likelihood (RML) - while the other two remaining methods consider they have ordinal properties -Unweighted Least Squares (ULS), and Robust Unweighted Least Squares (RULS). As far as we know, although there are some studies which use RULS method (Tsaousis et al., 2010; Wharton et al., 2009), it is also true that this estimation procedure has not been evaluated enough for the time being except Yang-Wallentin, Jöreskog and Luo (2010).

\begin{tabular}{cc}
\hline \multicolumn{2}{c}{ Is multivariate normality assumption fulfilled in observed variables? } \\
\hline YES & NO \\
(Symmetrical item distribution) & (Skewed item distribution) \\
\hline \multicolumn{2}{c}{ Observed variables are measured according to... } \\
\hline ...an interval scale: ML & ...an interval scale: RML \\
....an ordinal scale: ULS & ...an ordinal scale: RULS \\
\hline
\end{tabular}

Figure 1. Decisional criteria for applying the four methods compared in the study.

ML = Maximum Likelihood Method; ULS = Unweighted Least Squares Method; RML = Robust Maximum Likelihood Method; RULS = Robust Unweighted Least Squares Method.

As regards the estimation process, Pearson correlations are needed in ML or RML methods, and polychoric correlations in ULS or RULS ones. Moreover, according to the CFA assumption of multivariate normality mentioned above, ML and ULS methods are to apply when this assumption is fulfilled, otherwise RML and RULS methods are the suitable ones. It should be noted that in these two latter methods the asymptotic covariance (AC) matrix is involved in obtaining parameter estimations (Batista \& Coenders, 2000) as well as in $\chi^{2}$ LRT values when using LISREL software (Jöreskog, 2004).

Taking into account (as pointed out by Cliff \& Kyats, 2005; Göb, McCollin \& Ramalhoto, 2007; Kampen \& Swyngedouw, 2000) that the use of measurement instruments which require categorical responses from subjects is increasingly common in social research, and that this implies the use of ordinal scales, the present study aims to compare, by means of simulation studies, different estimation methods. For that purpose we focus in how affects the estimation method (ML, RML, ULS, and RULS) combined with the correlation matrix used (Pearson, polychoric) in Type I error and in one of the most important overall goodness of fit indices as RMSEA. Especially, we will focus on RULS due to the little research that has been conducted on its performance.

\section{Method}

In this simulation study three factors were manipulated: hypothesized model dimensions (3, 5 and 7 uncorrelated factors), sample size (250, 450, 650, 850) and items skewness (all items symmetric, all items asymmetric).

In the hypothesized model dimensions we used these three levels (3, 5 and 7) trying to represent most of the modern personality inventories. According to Comrey and Lee (1992) the values of the sample size could represent fair values $(\mathrm{N}=250)$ to excellent values $(\mathrm{N}=850)$ that are around 1000 participants. We keep as a constant the number of variables per factor. We used the minimum item required per factor (3 item per factor) for factor identification. Finally we used two levels of asymmetry (symmetric items; and items with a moderate level of skewness, \pm 1.3 ). According to Muthén and Kaplan (1985) the limit of skewness in real data is around \pm 2 .

Data generation and analysis were carried out using PRELIS 2 and LISREL 8 software (Jöreskog \& Sörbom, 1996a,b), while online free shareware R 2.12.0 provided the programming language: $R$ 2.0.0 "A Language and Environment" (2004).

Assuming a normal distribution $\mathrm{N}(0,1)$, we firstly generated the answers of the samples to 9,15 or 21 items (3, 5 
and 7 dimensions, respectively). Secondly, the answers were categorized according to a five-point scale so that: (a) the answers to all items have symmetric distribution; and (b) the answers to all items have asymmetric distribution (skewness was alternatively negative and positive). Finally, to determine the goodness of fit of the models, we conducted for each of the experimental conditions a confirmatory factor analysis with ML, RML, ULS and RULS estimators using Pearson, polychoric correlations and AC matrices as appropriate. The number of replications in each of the ( $3 \times 4 \times 2) 24$ experimental conditions was 30 because of the limitation motivated by the time of computing.

The threshold used to categorize the items were for:

symmetric items:

\begin{tabular}{|c|c|c|c|c|c|c|}
\hline If & & & $\mathrm{z}^{*}$ & $\leq$ & -1 & $\mathrm{z}$ is encoded as 1 , \\
\hline If & -1 & $<$ & $\mathrm{z}^{*}$ & $\leq$ & 0 & $\mathrm{z}$ is encoded as 2 \\
\hline If & 0 & $<$ & $\mathrm{z}^{*}$ & $\leq$ & 1 & $\mathrm{z}$ is encoded as 3 , \\
\hline If & 1 & $<$ & $\mathrm{z}^{*}$ & $\leq$ & 2 & $\mathrm{z}$ is encoded as 4 , \\
\hline If & 2 & $<$ & $\mathrm{z}^{*}$, & & & $\mathrm{z}$ is encoded as \\
\hline
\end{tabular}

negative skewed items (-1.3):

\begin{tabular}{|c|c|c|c|c|c|c|}
\hline If & & & $\mathrm{z}^{*}$ & $\leq$ & 0 & $\mathrm{z}$ is encoded as 1 , \\
\hline If & 0 & $<$ & $\mathrm{z}^{*}$ & $\leq$ & 1 & $\mathrm{z}$ is encoded as 2 \\
\hline If & 1 & $<$ & $\mathrm{z}^{*}$ & $\leq$ & 1.5 & $\mathrm{z}$ is encoded as 3 \\
\hline If & 1.5 & $<$ & $\mathrm{z}^{*}$ & $\leq$ & 2 & $\mathrm{z}$ is encoded as 4 \\
\hline If & 2 & $<$ & $\mathrm{z}^{*}$ & & & $\mathrm{z}$ is encoded as \\
\hline
\end{tabular}

positive skewed items:

$$
\begin{aligned}
& \text { If } \quad \mathrm{z}^{*} \leq-2 \quad \mathrm{z} \text { is encoded as } 1 \text {, } \\
& \text { If }-2<\mathrm{z}^{*} \leq-1.5 \mathrm{z} \text { is encoded as } 2 \text {, } \\
& \text { If }-1.5<\mathrm{z}^{*} \leq-1 \quad \mathrm{z} \text { is encoded as } 3 \text {, } \\
& \text { If }-1<\mathrm{z}^{*} \leq 0 \quad \mathrm{z} \text { is encoded as } 4 \text {, } \\
& \text { If } 0<\mathrm{z}^{*}, \quad \mathrm{z} \text { is encoded as } 5 \text {. }
\end{aligned}
$$

\section{Results}

\subsection{Symmetrical Item Distribution}

As can be seen in Table 1, when we apply ULS or RULS methods, percentages of C2 index for 3 factor models are high for samples of 250 subjects, but not for the remaining sample sizes. With regard to C4 index, the highest percentages of replications which maintain the null hypothesis correspond to 3 factor models whatever the sample size. In contrast, percentages related to C3 index are high to all sample sizes and number of factors.

In respect of ML and RML estimators, C1, C2 and C3 indexes show high percentages. It is worthy to note that the percentage values of C3 index are even greater than the ones reported for RULS method. Percentage levels of C4 index for 3 factor models are high along the different sample sizes, while they are pretty high for 5 factor models with 450 or 650 subjects and high for 850 subjects. Models of 7 factors with 850 subjects are the ones with the highest percentage of replications where the theoretical model shows adjustment with the empirical model.

RMSEA index percentages indicate an acceptable aproximation error to the empirical model, irrespective of the experimental condition. 
Table 1. Symmetrical item distribution results according to parameter estimation method, sample size and number of model factors: (a) Percentage of replications in which null hypothesis statistical $\chi^{2}$ LRT test was accepted, (b) Percentage of replications whose RMSEA index values were lower than 0.08 .

\begin{tabular}{|c|c|c|c|c|c|c|c|c|c|c|c|c|c|c|c|}
\hline \multirow[t]{3}{*}{$\mathrm{n}$} & \multirow[t]{3}{*}{ factors } & \multicolumn{10}{|c|}{ \% Ho accepted } & \multicolumn{4}{|c|}{$\%$ RMSEA $<0.08$} \\
\hline & & \multirow{2}{*}{$\begin{array}{c}\text { ULS } \\
\text { C2 }\end{array}$} & \multicolumn{3}{|c|}{ RULS } & \multicolumn{2}{|c|}{ ML } & \multicolumn{4}{|c|}{ RML } & \multirow{2}{*}{ ULS } & \multirow{2}{*}{ RULS } & \multirow{2}{*}{ ML } & \multirow{2}{*}{ RML } \\
\hline & & & C2 & C3 & C4 & $\mathrm{C} 1$ & $\mathrm{C} 2$ & C1 & $\mathrm{C} 2$ & C3 & C4 & & & & \\
\hline \multirow{3}{*}{250} & 3 & 90 & 90 & 90 & 93.33 & 90 & 90 & 90 & 90 & 90 & 90 & 100 & 100 & 100 & 100 \\
\hline & 5 & 36.67 & 70 & 96.67 & 20 & 86.67 & 96.67 & 86.67 & 96.67 & 100 & 43.33 & 100 & 100 & 100 & 100 \\
\hline & 7 & 13.33 & 13.33 & 90 & 0 & 86.67 & 90 & 86.67 & 90 & 100 & 0 & 100 & 100 & 100 & 100 \\
\hline \multirow{3}{*}{450} & 3 & 50 & 50 & 90 & 86.67 & 90 & 90 & 90 & 90 & 93.33 & 90 & 100 & 100 & 100 & 100 \\
\hline & 5 & 30 & 30 & 96.67 & 53.33 & 93.33 & 96.67 & 93.33 & 96.67 & 100 & 86.67 & 100 & 100 & 100 & 100 \\
\hline & 7 & 16.67 & 16.67 & 90 & 0 & 86.67 & 90 & 86.67 & 90 & 100 & 20 & 100 & 100 & 100 & 100 \\
\hline \multirow{3}{*}{650} & 3 & 60 & 60 & 100 & 86.67 & 93.33 & 93.33 & 93.33 & 93.33 & 100 & 100 & 100 & 100 & 100 & 100 \\
\hline & 5 & 26.67 & 26.67 & 93.33 & 53.33 & 90 & 90 & 90 & 90 & 100 & 83.33 & 100 & 100 & 100 & 100 \\
\hline & 7 & 10 & 10 & 96.67 & 10 & 86.67 & 86.67 & 86.67 & 86.67 & 100 & 56.67 & 100 & 100 & 100 & 100 \\
\hline \multirow{3}{*}{850} & 3 & 56.67 & 56.67 & 93.33 & 93.33 & 93.33 & 93.33 & 93.33 & 93.33 & 100 & 100 & 100 & 100 & 100 & 100 \\
\hline & 5 & 30 & 30 & 93.33 & 76.67 & 93.33 & 93.33 & 93.33 & 93.33 & 96.67 & 96.67 & 100 & 100 & 100 & 100 \\
\hline & 7 & 13.33 & 13.33 & 100 & 40 & 93.33 & 96.67 & 93.33 & 96.67 & 100 & 90 & 100 & 100 & 100 & 100 \\
\hline
\end{tabular}

ULS = Unweighted Least Squares Method

RULS $=$ Robust Unweighted Least Squares Method

ML = Maximum Likelihood Method

RML = Robust Maximum Likelihood Method

C1 = Minimum Fit Function Chi-Square

C2 = Normal Theory Weighted Least Squares Chi-Square

C3 = Satorra-Bentler Scaled Chi-Square

C4 = Chi-Square Corrected for Non-Normality

\subsection{Asymmetrical Item Distribution}

As shown in Table 2, there are no replications for C2 index when ULS or RULS estimators are considered, except a few percentage (3.33\%) for 5 factor models with 450 subjects. The highest percentages for C3 index belong to 5 and 7 factor models, especially for 850 subjects samples, since all replications are involved. Finally, for C4 index only 5 factor models with a sample size of 850 have a pretty high percentage of replications where the null hypothesis is hold.

Concerning ML and RML estimation methods, there is a similar trend in C1 and C2 indices in the sense that percentual values are higher for 5 factor models compared to 3 and 7 factor models regardless of the sample size. In addition, in particular for 250 subjects samples, percentages of C3 index are high for all sample sizes of 5 factor models as well as for samples with 250, 450 and 650 subjects of 7 factor models. With respect to C4 index, compared to 3 and 7 factor models, 5 factor models have a higher level of replications for which the null hypothesis is accepted, showing an upward trend in percentage as long as sample sizes increase.

The percentages computed from RMSEA index show that not all replications reach an acceptable aproximation error. The results for 3 factor models depend on the estimation method and the sample size. The lowest percentages correspond to ULS estimation method, especially in samples with 250 and 650 subjects, where no replication is found. 
Table 2. Skewed item distribution results according to parameter estimation method, sample size and number of model factors: (a) Percentage of replications in which null hypothesis statistical $\chi^{2}$ LRT test was accepted, (b) Percentage of replications whose RMSEA index values were lower than 0.08 .

\begin{tabular}{|c|c|c|c|c|c|c|c|c|c|c|c|c|c|c|c|}
\hline \multirow[t]{3}{*}{$\mathrm{n}$} & \multirow[t]{3}{*}{ factors } & \multicolumn{10}{|c|}{ \% Ho accepted } & \multicolumn{4}{|c|}{$\%$ RMSEA $<0.08$} \\
\hline & & \multicolumn{2}{|l|}{ ULS } & \multicolumn{2}{|c|}{ RULS } & \multicolumn{2}{|c|}{ ML } & \multicolumn{4}{|c|}{ RML } & \multirow{2}{*}{ ULS } & \multirow{2}{*}{ RULS } & \multirow{2}{*}{ ML } & \multirow{2}{*}{ RML } \\
\hline & & $\mathrm{C} 2$ & C2 & C3 & C4 & C1 & $\mathrm{C} 2$ & C1 & C2 & C3 & C4 & & & & \\
\hline \multirow{3}{*}{250} & 3 & 0 & 0 & 30 & 13.33 & 16.67 & 20 & 3.33 & 3.33 & 13.33 & 23.33 & 0 & 90 & 93.33 & 86.67 \\
\hline & 5 & 3.33 & 3.33 & 96.67 & 16.67 & 73.33 & 63.33 & 73.33 & 73.33 & 100 & 50 & 100 & 100 & 100 & 100 \\
\hline & 7 & 0 & 0 & 96.67 & 0 & 36.67 & 36.67 & 36.67 & 36.67 & 100 & 0 & 100 & 100 & 100 & 100 \\
\hline \multirow{3}{*}{450} & 3 & 0 & 0 & 6.67 & 3.33 & 6.67 & 6.67 & 6.67 & 6.67 & 36.67 & 30 & 10 & 100 & 100 & 100 \\
\hline & 5 & 0 & 0 & 96.67 & 53.33 & 30 & 33.33 & 30 & 33.33 & 93.33 & 63.33 & 100 & 100 & 100 & 100 \\
\hline & 7 & 0 & 0 & 96.67 & 6.67 & 23.33 & 20 & 23.33 & 20 & 96.67 & 3.33 & 100 & 100 & 100 & 100 \\
\hline \multirow{3}{*}{650} & 3 & 0 & 0 & 0 & 0 & 0 & 0 & 0 & 0 & 3.33 & 3.33 & 0 & 96.67 & 100 & 100 \\
\hline & 5 & 0 & 0 & 93.33 & 70 & 30 & 20 & 30 & 20 & 86.67 & 70 & 100 & 100 & 100 & 100 \\
\hline & 7 & 0 & 0 & 96.67 & 13.33 & 6.67 & 3.33 & 6.67 & 3.33 & 93.33 & 20 & 100 & 100 & 100 & 100 \\
\hline \multirow{3}{*}{850} & 3 & 0 & 0 & 0 & 0 & 0 & 0 & 0 & 0 & 0 & 0 & 3.33 & 100 & 100 & 100 \\
\hline & 5 & 0 & 0 & 100 & 83.33 & 16.67 & 13.33 & 16.67 & 13.33 & 90 & 73.33 & 100 & 100 & 100 & 100 \\
\hline & 7 & 0 & 0 & 100 & 36.67 & 3.33 & 3.33 & 3.33 & 3.33 & 66.67 & 20 & 100 & 100 & 100 & 100 \\
\hline
\end{tabular}

ULS = Unweighted Least Squares Method

RULS $=$ Robust Unweighted Least Squares Method

ML = Maximum Likelihood Method

RML = Robust Maximum Likelihood Method

$\mathrm{C} 1=$ Minimum Fit Function Chi-Square

C2 $=$ Normal Theory Weighted Least Squares Chi-Square

C3 = Satorra-Bentler Scaled Chi-Square

C4 = Chi-Square Corrected for Non-Normality

\section{Discussion}

According to $\chi^{2}$ LRT results from the experimental conditions, when ML estimator is applied as there is multivariate normality (all items response distribution is symmetric) (Table 1), the hypothesized and the empirical model show fit at a high percentage of replications whatever the number of dimensions, sample size of the hypothesized model. Using RML as multivariate normality assumption requirement in ML is not fulfilled (item distribution is skewed) (Table 2), adjustment between the hypothesized and the empirical model takes place at a high rate of replications for 5 factor models with all sample sizes considered and for 7 factor models with 250, 450 and 650 subjects samples according to C3 index, also known as "Satorra-Bentler Scaled Chi-square" and considered as the best index when items distribution is skewed (Satorra \& Bentler, 1994).

The measurement scale of an instrument is an important topic related to construct validity (Flora, Finkel, \& Foshee, 2003; Jöreskog, 2001; Maydeu \& D' Zurilla, 1995). Related to this matter, an important point to remember is that both ML and RML estimation methods assume the continuous nature of observed variables. In Likert scales the ordinal measurement nature of observed variables is in conflict with these methods. In this respect, according to Jöreskog and Sörbom (1989), when the observed variables are considered as if they are of continuous instead of ordinal nature and a ML method is applied (which involves Pearson correlations), distorted parameters estimations as well as incorrect $\chi^{2}$ goodness of fit indices can be obtained. It is also the case of RML, even if it can be a solution when multivariate normality assumption requirement for application of ML is not fulfilled.

ULS and RULS estimators assume observed variables are of ordinal nature and use polychoric correlation 
coefficients. Regarding ULS method, from data in Table 1 it can be seen that only 3 factor models with 250 subjects have the highest percentages of replications with adjustment between the hypothesized and the empirical model when multivariate normality assumption is fulfilled. On the contrary, when observed variables item distribution is skewed and therefore RULS estimator is applied, these high percentages take place for 5 or 7 factors models, particularly with 850 subjects sample, according to C3 index (Table 2). In addition, according to RMSEA results, hypothesized models have a high complexity level, so discard processes are needed from extra-statistical criteria in order to know which of those models have sense within the theoretical frame which generated them. Further investigations could be linked to theoretical models complexity topic, as items sharing between different factors or second-order CFA models. Within Exploratory Factor Analysis should be mentioned Garrido, Abad and Ponsoda (2011) contributions as a starting point in order to decide the number of factors to retain when working with ordinal observed variables.

This simulation study on Likert scales expand the results obtained by Holgado, Chacón, Barbero and Vila (2010) whereby using polychoric correlations implies an advantage over Pearson correlations. In turn, Jöreskog and Sörbom (1989) state polychoric correlations are more proper than Pearson's when observed variables are ordinal. On this basis, when using Likert scales, selecting estimation methods which use polychoric correlations, such as ULS or RULS, seems to be preferable.

Finally we would like remark some practical recommendations:

1. With small sample sizes (250 subjects) the ULS method is recommended when the distribution of the variables is symmetrical, and the number of factors is 3 .

2. With either of the sample sizes included in our study (250, 450, 650 or, particularly, 850 subjects) the RULS method is recommended when the variables show a skewed distribution, and the number of factors is 5 or 7 .

3. According to the values displayed by RMSEA index, paying attention to extra-statistical criteria is recommendable in order to discard hypothesized models with high complexity levels.

We took this work as a first approximation to the study of the performance of different estimation methods with ordinal variables. In this sense, we have tried to simulated habitual conditions in real settings. Despite the above recommendation, besides being a simulation study, results are influenced by several factors. First, answers are here categorized on a five-point Likert scale. It would be worthy to undertake research about number of response categories and factorial validity. According to several CFA investigations (see Babakus, Ferguson, \& Jöreskog, 1987; Dolan, 1994; Green, Akey, Fleming, Hershberger, \& Marquis, 1997; Hutchinson \& Olmos, 1998) a greater number of categories leads to an increasing loss of information and, in turn, to a rising attenuation of items relationships. Second, the set of threshold values applied in order to categorize the answers of the scale may affect the results of this study. Future studies should compare the findings obtained here with another widths within the threshold values for skewed items distributions, even with model fit after determining a certain skewness/kurtosis level. In addition, many important CFA goodness of fit indices, so as CFI, GFI, AGFI, NFI, NNFI or PNFI, may help to examine the complexity of the models this study comprised. Future research may also investigate items fiability. In this sense, according to Cea (2004), not only empirical variables influences from latent and other observed variables, but also from error terms should be measured.

\section{Conclusions}

As a general conclusion, the measurement scale of the data is an important matter to take into account when we test construct validity through factor analysis (Flora, Finkel, \& Foshee, 2003; Jöreskog, 2001; Maydeu \& D' Zurilla, 1995). The ability of hypothesized models to explain the observed data, indicated by goodness of fit, can be biased due to an incorrect use of parameter estimation methods. In other words, coherence between estimators and instrument of measurement is necessary in order to reproduce accurately the construct variables relationships.

\section{References}

Babakus, E., Ferguson, C. E., \& Jöreskog, K. G. (1987). The sensivity of confirmatory maximum likelihood factor analysis to violations of measurement scale and distributional assumptions. Journal of Marketing Research, 24, 222-229.

Batista, J. M., \& Coenders, G. (2000). Modelos de ecuaciones estructurales. Madrid: La Muralla.

Bisquerra, R. (1989). Introducción conceptual al análisis multivariable. Un enfoque informático con los paquetes estadísticos SPSS-X, LISREL y SPAD (Vol. 2). Barcelona: PPU.

Bollen, K. A. (1989). Structural equations with latent variables. New York: Wiley. 
Byrne, B. M. (1998). Structural equation modeling with LISREL, PRELIS, and SIMPLIS: Basic concepts, applications and programming. New Jersey: Lawrence Erlbaum Associates.

Cea, M. A. (2004). Análisis multivariable. Teoría y práctica en la investigación social ( $2^{\text {nd }}$ ed.). Madrid: Síntesis.

Cliff, N., \& Kyats, J. A. (2005). Ordinal measurement in the behavioural sciences. New Jersey: Lawrence Erlbaum.

Coenders, G., \& Saris, W. E. (1995). Categorization and measurement quality. The choice between Pearson and Polychoric correlations. In W. E. Saris \& Á. Münnich (Eds.), The Multitrait-Multimethod approach to evaluate measurement instruments (pp. 125-144). Budapest: Eötvös University Press.

Comrey, A.L., \& Lee, H.B. (1992). A first course in factor analysis ( $2^{\text {nd }}$ ed.). Hilldsdale, NJ: Erlbaum.

DiStefano, C. (2002). The impact of categorization with confirmatory factor analysis. Structural Equation Modeling, 9 (3), 327-346.

Dolan, C. V. (1994). Factor analysis of variables with 2, 3, 5 and 7 response categories: A comparison of categorical variable estimator using simulated data. British Journal of Mathematical and Statistical Psychology, 47, 309-326.

Ferrando, P., \& Anguiano-Carrasco, C. (2010). El Análisis Factorial como técnica de investigación en Psicología. Papeles del Psicólogo, 31(1), 18-33. Retrieved from http://www.papelesdelpsicologo.es/pdf/1137.pdf

Finch, J. F., West, S. G., \& MacKinnon, D. P. (1997). Effects of sample size and nonormality on the estimation of mediated effects in latent variable models. Structural Equation Modeling, 4, 87-107.

Finney, S.J., \& DiStefano, C. (2006). Non-normal and categorical data in structural equation modelling. In G.R. Hancock \& R.O. Mueller (Eds.), Structural Equation Modelling: A second course. (pp. 269-314). Greenwich: Information Age Publishing.

Flora, B. F., Finkel, E. J., \& Foshee, V. A. (2003). Higher order factor structure of a self-control test: evidence from confirmatory factor analysis with polychoric correlations. Educational Psychological Measurement, 63 (1), 112-127.

Garrido, L. E., Abad, F. J., \& Ponsoda, V. (2011). Performance of Velicer's minimum average partial factor retention method with categorical variables. Educational and Psychological Measurement, 71 (3), 551-570. http://www.dx.doi.org/10.1177/0013164410389489

Gilley, W. F., \& Uhlig, G. E. (1993). Factor Analysis and Ordinal Data. Education, 114 (2), 258-264.

Göb, R., McCollin, C. H., \& Ramalhoto, M. F. (2007). Ordinal methodology in the analysis of Likert scales. Quality \& Quantity, 41 (5), 601-626. http://www.dx.doi.org/10.1007/s11135-007-9089-z

Green, S.B., Akey, T.M., Fleming, K.K., Hershberger, S.L., \& Marquis, J.G. (1997). Effect of the number of the scale points on fit indices in confirmatory factor analysis. Structural Equation Modeling: A Multidisciplinary Journal, 4, 108-120.

Holgado, F. P., Chacón, S., Barbero, I., \& Vila, E. (2010). Polychoric versus Pearson correlations in exploratory and confirmatory factor analysis of ordinal variables. Quality and Quantity, 44, 153-166. http://www.dx.doi.org/10.1007/s11135-008-9190-y

Hutchinson, S. R., \& Olmos, A. (1998). Behaviour of descriptive fit indexes in confirmatory factor analysis using ordered categorical data. Structural Equation Modeling, 5, 344-364.

Johnson, D. R., \& Creech, J. C. (1983). Ordinal measures in multiple indicator models: A simulation study of categorization error. American Sociological Review, 48, 398-407.

Jöreskog, K. G. (2001). Analysis of ordinal variables 2. Cross-Sectional Data. Text of the Workshop "Structural equation modelling with LISREL 8.51”. Jena: Friedich-Schiller-Universität, Jena.

Jöreskog, K. G. (2004). On Chi-Squares for the Independence Model and Fit Measures in LISREL. Retrieved from http://www.ssicentral.com/lisrel/techdocs/ftb.pdf

Jöreskog, K.G., \& Sörbom, D. (1989). LISREL 7: A guide to the program and applications. Chicago: Scientific Software International, Inc.

Jöreskog, K.G., \& Sörbom, D. (1996a). LISREL 8: User's reference guide. Chicago: Scientific Software International, Inc.

Jöreskog, K.G., \& Sörbom, D. (1996b). PRELIS 2: User’s reference guide. Chicago: Scientific Software 
International, Inc.

Kampen, J., \& Swyngedouw, M. (2000). The ordinal controversy revisited. Quality \& Quantity, 34, 87-102.

Maydeu, A., \& D’Zurilla, T. J. (1995). A factor analysis of the social problem-solving inventory using polychoric correlations. European Journal of Psychological Assessment, 11 (2), 98-107.

Mels, G. (2006). LISREL for Windows: Getting Started Guide. Lincolnwood, IL: Scientific Software International, Inc. Retrieved from http://www.ssicentral.com/lisrel/techdocs/GSWLISREL.pdf

Muthén, B., \& Kaplan, D. (1985). A comparison of some of the methodologies for the factor analysis of non-normal Likert variables. British Journal of Mathematical and Statistical Psychology, 38, 171-189.

Muthén, B., \& Kaplan, D. (1992). A comparison of some of the methodologies for the factor analysis of non-normal Likert variables: A note on the size of the models. British Journal of Mathematical and Statistical Psychology, 45, 19-30.

O’Brien, R. M. (1985). The relationship between ordinal measures and their underlying values: Why all the disagreement? Quality and Quantity, 19, 265-277.

Quiroga, A. M. (1992). Studies of the polychoric correlation and other correlation measures for ordinal variables. Doctoral dissertation. University of Uppsala.

Saris, W., Van Wijk, T., \& Scherpenzeel, A. (1998). Validity and reliability of subjective social indicators. Social Indicators Research, 45, 173-199.

Satorra, A., \& Bentler, P. M. (1994). Corrections tot test statistics and standard errors in covariance structure analysis. In A. Von Eye \& C. Clogg (Eds.), Latent variables analysis: applications to developmental research (pp. 399-419). Thousand Oaks: Sage.

Schumacker, R. E., \& Lomax, R. G. (1996). A beginner's guide to structural equation modeling. New Jersey: Lawrence Erlbaum Associates.

Tsaousis, I., Taylor, G., Quilty, L., Georgiades, S., Stavrogiannopoulos, M., \& Bagby, R. M. (2010). Validation of a Greek adaptation of the 20-item Toronto Alexithymia Scale. Comprehensive Psychiatry, 51, 443-448. http://www.dx.doi.org/10.1016/j.comppsych.2009.09.005

West, S. G., Finch, J. F., \& Curran, P. J. (1995). Structural equation models with nonnormal variables: problems and remedies. In R. H. Hoyle (Ed.), Structural Equation Modeling: concepts, issues and applications (pp. 56-75). Thousand Oaks (CA): Sage.

Wharton, W., Dowling, M., Khosropourb, C. M., Carlsson, C. Asthana, S., \& Gleason, C. E. (2009). Cognitive benefits of hormone therapy: Cardiovascular factors and healthy-user bias. Maturitas, 64, 182-187. http://www.dx.doi.org/10.1016/j.maturitas.2009.09.014

Yang-Wallentin, F., Jöreskog, K., \& Luo, H. (2010). Confirmatory Factor Analysis of Ordinal Variables With Misspecified Models. Structural Equation Modeling: A Multidisciplinary Journal, 17, 392-423. http://www.dx.doi.org/10.1080/10705511.2010.489003

\section{(cc) BY}

This work is licensed under a Creative Commons Attribution 3.0 License. 